\title{
Is there gender bias in research grant success in social sciences?: Hong Kong as a case study
}

Paul Siu Fai Yip ${ }^{1 凶}$, Yunyu Xiao ${ }^{2}$, Clifford Long Hin Wong ${ }^{3} \&$ Terry Kit Fong Au ${ }^{4}$

Despite growing attention to gender disparities in higher education, women in academia still receive less research funding and recognition. Previous research on this gender gap has focused on biomedical, science, technology, engineering, and mathematics in the Westrelatively silent on social sciences and Asia. This study examined how well staff gender, submission rate, success rate, and amount per award could predict annual changes in the number and amount of grant funding for academic years 2015/2016-2020/2021 in the Faculty of Social Science at the University of Hong Kong, a leading institution in social sciences in Asia. Decomposition analysis revealed that, compared to men, women had higher submission rates, which significantly contributed to an increase in the number of awards for the University in recent years in two major funding mechanisms (namely, General Research Fund and Early Career Scheme), especially from 2019/2020 to 2020/2021. Women also outperformed men in the success rate in the Early Career Scheme (i.e., within the first three years of faculty appointment). Both submission rate and success rate contributed to changes in award number and the total amount for the University over time. Overall, women had a higher submission rate, successful rate, and amount per award than their male counterparts. We have identified good practices and distinctive contextual factors in Hong Kong that likely contribute to the lack of gender bias for research grant application results in Social Sciences.

\footnotetext{
${ }^{1}$ Department of Social Work and Social Administration, The University of Hong Kong, Hong Kong SAR, China. ${ }^{2}$ Indiana University-Purdue University Indianapolis, 902 W. NEW YORK STREET, ES4119, Indianapolis, IN 46202-5197, USA. ${ }^{3}$ Centre for Suicide Research and Prevention, The University of Hong Kong, Hong Kong SAR, China. ${ }^{4}$ The University of Hong Kong President's Office, Hong Kong SAR, China. ${ }^{凶}$ email: sfpyip@hku.hk
} 


\section{Introduction}

ender disparity has been noted and debated across research domains, disciplines, and countries for over two decades (Ding et al., 2006; Symonds et al., 2006; Larivière et al., 2013; Shen, 2013; West et al., 2013; Sheltzer, 2018; Grogan, 2019; Witteman et al., 2019a; Xiao et al., 2020). Women in academia take longer to publish and receive less credit (Symonds et al., 2006; West et al., 2013; Grogan, 2019). Woman-led articles get fewer citations even in high impact journals (Larivière et al., 2013; Ghiasi et al., 2015), and women are less represented among journal referees (Lerback and Hanson, 2017). In terms of recruitment and promotion, women academics are not only less likely to be hired as new faculty members (Moss-Racusin et al., 2012; Sheltzer, 2018), but also under-represented in senior professorial and managerial roles in higher education institutions (HEIs; Ovseiko et al., 2016; Xiao et al., 2020). In particular, gender disparity persists in biomedicine (Edmunds et al., 2016; Sheltzer, 2018), science, technology, engineering, and mathematics (STEM; Holmes et al., 2008; National Research Council, 2010; Finkel, 2013; Latimer et al., 2019). Underrepresentation of women in the academia has prevailed in the United Kingdom (UK; Bedi et al., 2012; Schmidt et al., 2020), the United States (US; Pohlhaus et al., 2011; Ginther et al., 2016), Australia (Finkel, 2013), Canada (Witteman et al., 2019a, 2019b), Denmark (Watson and Hjorth, 2015), and China (Postiglione and Tang, 2008; Aiston, 2014; Ma et al., 2018; Aiston et al., 2020).

In response, gender-equity initiatives, such as the Athena SWAN of the Equality Challenge Unit (ECU, 2019a) in the UK and the ADVANCE program of the National Science Foundation (NSF, 2001) in the US, were launched to promote gender diversity and equity (DeAro et al., 2019). HeForShe University IMPACT Champions across eight countries and five continents, under the United Nations' auspices, set out to promote gender-equal campus since 2016 (UN Women, 2016). Yet, despite advocacy and debates, imbalance persists. Proactive structural and climate changes in HEIs, funding organizations, and societies at large are still much needed (Zakaib, 2011; Nielsen et al., 2018).

Research grant funding seems to be a key driver of gender inequality in academia (Boyle et al., 2015). Research grants are essential for academic career success (Bedi et al., 2012; Witteman et al., 2019b). In particular, funding received in an early career significantly contributes to retaining female scholars in the academic pipeline (van den Besselaar and Leydesdorff, 2009; Zhang et al., 2018). Successfully securing research funding in the early stage of the tenure-track is key to get tenure and promotion and considered an important criterion for research excellence (Jung, 2012; Aiston, 2014). Gender diversity in funded research can also drive scientific innovation, team development, and ultimately enhance research quality (Nielsen et al., 2018; Witteman et al., 2019a).

Prior studies in biomedical and STEM fields have consistently revealed gender disparities in grant submission and success rates (Bedi et al., 2012; McAllister et al., 2016; Burns et al., 2019; Grogan, 2019; Witteman et al., 2019a). An analysis of research grants from the Wellcome Trust, a major funder in the UK, showed that fewer women applied for grants, and those were awarded received much smaller grants on average than did men during 2000 and 2008 (Bedi et al., 2012). Similar grant-seeking gender disparity was observed for the Canadian Institutes of Health Research (CIHR) Foundation (Burns et al., 2019; Witteman et al., 2019a), the US National Institutes of Health (NIH), and NSF (Pohlhaus et al., 2011; Hechtman et al., 2018; Grogan, 2019), and across Europe (Watson and Hjorth, 2015; BautistaPuig et al., 2019). For example, in Denmark, even taking into account of the "Younger women Devoted to a UNiversity career" (YDUN) research awards, male principal investigators on average still received a greater grant amount than their female colleagues (Watson and Hjorth, 2015).

Beyond STEM disciplines, however, gender disparity in research funding was less consistently reported. One meta-analysis, including science, social science, and humanities grants, found male applicants had a success rate of $7 \%$ higher than female applicants (Bornmann et al., 2007). Similar results were reported for NIH RO1 grants in the US (Kaatz et al., 2016) and the Australian Research Council's Discovery Grant (Symonds et al., 2006). On the other hand, a large study found no gender disparity in grant success in the US (Marsh et al., 2011; Pohlhaus et al., 2011; Forscher et al., 2019).

To date, relatively little is known about gender parity for nonSTEM disciplines and even less for such disciplines in Asia. One study on UK Economic and Social Research Council (ESRC) research grants revealed no gender difference in social scientists for success rate and award size. Among junior academics, women indeed seemed slightly more successful than men (Boyle et al., 2015). Why might gender parity in research funding be better for social sciences than STEM disciplines? Candidate explanations include higher female representation (which disrupts conventional gender expectation in responsibilities and hierarchy), engagement of feminist or at least less gender-stereotyped research practices (which disrupts male power dominance), and creation of critical knowledge of awareness (which encourages male social scientists to share a respect for female scholars; Boyle et al., 2015).

To date, published research remains quite silent on gender (dis)parity in funding practice and success for social sciences in a non-Western context. One might expect gender inequality to be more severe in Asia due to Confucius's teaching and traditional male domination (Chang et al., 2019). Will the slight female edge for social sciences observed in the UK exist in a more patriarchal society (e.g., Chinese culture)?

Hong Kong provides a unique case internationally to explore the position of academic women. Hong Kong culture is considered a mix of East and West. While the traditional Asian culture still emphasizes women's role as wives, mothers, and homemakers (Luke, 2000), interacting with other cultures has weakened male dominance in the families and work environments in Hong Kong (Postiglione and Tang, 2008). As a leading International Financial Center, Hong Kong embraces economic and academic freedom, and the universities in Hong Kong have consistently demonstrated excellence in research (Aiston and Jung, 2015). Research in Hong Kong has been found to be highly internationalized and well-recognized (Jung, 2012; Tang, 2018, 2019), as indicated, for instance, by Quacquarelli Symonds (QS) rankings of universities.

Hong Kong also distinguishes itself from many global counterparts because most middle-class families employ live-in foreign domestic helpers, resulting in the less gendered division of labor at home for the employers. Female academics and other professionals in Hong Kong may well have fewer household chores than their counterparts overseas. In addition, Hong Kong Labor and Welfare Bureau successfully extended maternity leave from 10 to 14 weeks in Hong Kong, with 80 percent of the mothers' wages covered.

Despite the interesting interplay of these cultural factors, research on gender (dis)parity regarding research grant funding in Hong Kong remains limited (Aiston, 2014). Most existing studies hark back to the 2008 Changing Academic Profession (CAP) survey, which found that women published less than men in general. Yet, Aiston (2014) found that women in the humanities and social sciences (HSS) at both senior and junior levels reported more likely to publish peer-reviewed articles. The latest 
CAP survey was done in 2008 also revealed that women received less public research funding than men (Teodorescu, 2000; Jung, 2012; Aiston, 2014; Aiston and Jung, 2015). Based on interviews with 16 established female professors in HSS, Ruan (2020) identified managerial and neoliberal practices in universities as major obstacles and biases that diminish research opportunities for women academics in Hong Kong. Major questions remain: Are there measurable gender differences in public research funds in social science disciplines in terms of submission rate, success rate, and average award size? Do their contributing factors differ for men and women?

In the present study, we focused on how characteristics of eligible applicants (e.g., gender, career stage, submission rate) might predict success rates and award amounts for government funding in the Faculty of Social Sciences (FOSS) at the University of Hong Kong (HKU). Known for its academic excellence, HKU ranked 22nd in the overall QS ranking (Quacquarelli Symonds, 2020), and 35th in the Times Higher Education (2020) World University Rankings. FOSS in HKU ranked 3rd in Asia, with about 100 faculty staff eligible to apply for government research grants. It has five departments (i.e., Geography, Politics \& Political Administration, Psychology, Social work \& Social Administration, Sociology) and one center (Journalism and Media Studies Center). Founded in 1911, HKU is the oldest University in Hong Kong; its FOSS could be a useful reference for universities in Asia.

Our study also took into account of career stage. Early-career female applicants have been found comparable to male applicants in submission and success rates and grant amounts. Still, women received fewer research grants when they moved to more senior positions (Boyle et al., 2015). For grants with longer project duration in particular (e.g., RO1 in the US), male researchers have a higher success rate and larger award amounts (Pohlhaus et al., 2011). The Research Grants Council (RGC) of Hong Kong under the University Grants Committee (UGC) has two major funding mechanisms for all disciplines: General Research Fund (GRF) and Early Career Scheme (ECS) awards (University Grants Committee, 2020d). For GRF, all academic staff (Professors, Associate Professors, Assistant Professors) who have a full-time appointment in a UGC-funded institution (University Grants Committee, 2020c) are eligible to apply. ECS applicants, however, are restricted to Assistant Professors (or equivalent) who are within the first three years of their full-time academic appointment (University Grants Committee, 2020a). To better understand the gender parity in research funding performance, which can be related to the career stage, we investigated GRF and ECS applications and outcomes separately.

We pay particular attention to four "myths" about why gender disparity existed in research funding for STEM and biomedicine (Mejia, 2010; Zakaib, 2011; Shen, 2013; Ovseiko et al., 2017; Ma et al., 2018; Sheltzer, 2018).

Myth 1: Men are better represented among faculty members (staff gender ratios).

Myth 2: Men are more likely to submit grant applications (submission rates).

Myth 3: Men's applications are more likely to succeed (success rates).

Myth 4: Men won larger research awards than women (award amounts)

This study, therefore, examined gender (dis)parities in research funding by focusing on gender ratios of eligible staff, submission rates, success rates, award amounts, and how these changed over five successive pairs academic years from 2015/16 to 2020/21. We used the decomposition method (Yip et al., 2017) to segregate each effect, namely, the number of staff, submission rate, and successful rate from the overall effect, separately for GRF and ECS by gender in FOSS at HKU. The decomposition method allowed us to examine the impact of individual predictors empirically on the successive annual changes in the number of awards and award amounts during the study period (2015/16-2020/21). In the latest research grant exercise $(2020 / 21)$, HKU has secured the highest number of approved projects in the GRF and ECS schemes overall, the largest share of funding in both schemes, and the highest number of funded projects specifically under the Humanities \& Social Sciences Panel among the eight UGCfunded universities (University Grants Committee, 2020a). Therefore, the HKU database offered a substantial amount of data on the variables of interest in this study.

\section{Methods}

Data and measures. To identify annual changes in grant funding in FOSS at HKU, the eligible numbers of applicants, submission rates, success rates, and total funding amounts separated by gender from 2015/16 to 2020/21 were obtained from the FOSS at $\mathrm{HKU}$ and were analyzed in order to improve research funding performance. The data were stratified by GRF and ECS among the eligible staff. Gender information was based on applicants' self-reports on the grant applications. Approval was obtained from the Human Research Ethics Committee at HKU (HREC Reference Number: EA200125).

Outcomes. Two grant application outcomes were assessed: (1) whether or not a GRF/ECS application was funded and (2) its award amount. Information on GRF/ECS successful applications and award amounts is publicly available on the UGC website (University Grants Committee, 2020b). Access to information on the number of submissions by gender and funding scheme (GRF vs. ECS) was granted by the Dean of FOSS at HKU.

Indicators. We examined four indicators: number of eligible staff, submission rate, success rate, and average award amount (in HKD '000; USD $1=\mathrm{HKD} \quad 7.8 ; \quad$ GBP $1=\mathrm{HKD} \quad 9.8$, approximately).

Statistical analysis. We first examined the descriptive statistics of overall and gender-specific annual changes in GRF/ECS awards from $2015 / 2016$ to $2020 / 2021$. Second, a decomposition analysis was conducted, focusing on how gender contributed to (1) number of awards and (2) award amounts. We created a threefactor (number of eligible staff, submission rate, and success rate) decomposition formula for the change in the number of awards (Appendix 1 - [i]) and a four-factor decomposition formula (number of eligible staff, submission rate, success rate, and average award amount) for the change in the total award amount for the entire FOSS (Appendix 1- [ii]). The summation of the components will add to $100 \%$. Both decomposition analyses were stratified by gender.

The decomposition effects quantify how much of the annual changes in the number and total amount of awards in FOSS was attributable to the number of eligible staff, the submission rate, the success rate, the average amount per award, and by gender. The three effects and the four effects were used to explain, respectively, the change in the number and total amount of GRF/ ECS awards. The decomposition method allows us to empirically examine the impact of the number of eligible staff, the number of submissions, and the number of successful applications on the change of the grant awards. The method is useful in delineating the effects by gender in previous studies (e.g., Madden, 2010; Hosseinpoor et al., 2012; Kwok et al., 2017; Yip et al., 2017). The proposed decomposition is not unique, and other factors can be used. Nevertheless, the number of eligible applicants, submission 
rate, and the success rate are the significant factors of interest here to account for gender parity in research grant application performance.

\section{Results}

Descriptive statistics. Table 1 presents the changes of GRF/ECS in $2015 / 2016$ to $2020 / 2021$. Over this study period, the gender composition of eligible applicants for GRF/ECS grants in FOSS was about $57.4 \%$ men and $42.6 \%$ women, which dovetailed the academic staff gender composition of $57 \%$ and $43 \%$ in 2018 (i.e., mid-way of the study period). By way of comparison, Duke University in the US, with similar QS ranking as HKU, reported having $62 \%$ men and $38 \%$ women among its academic staff in Social Sciences in 2018 (Duke University, 2020).

The overall submission rate and success rates were $58.2 \%$ and $30.9 \%$ for FOSS at HKU during the study period, respectively. The overall submission rate was higher for women $(59.2 \%)$ than men $(57.4 \%)$, and the overall success rate was also higher for women $(33.1 \%)$ than men (29.3\%). The average amount per award is about the same, $\mathrm{HK} \$ 692 \mathrm{~K}$ and $\mathrm{HK} \$ 655 \mathrm{~K}$, respectively. Numerically, women have done better than men for these three important indicators.

For some of the changes during the study period, the submission rate reduction offset the impact of success rate improvement on the number of awards and the total amount awarded. For example, the submission rates among women dropped from $65.9 \%$ to $50.0 \%$ for the period $2015 / 16$ to $2017 / 18$, followed by a gradual increase to $75.6 \%$ at $2020 / 21$, whereas the trend of submission rates among men rose steadily between 2016/ 17 and 2019/20 (49.2-67.7\%) and then dropped to 59.7\% in 2020/ 2021. Across our entire study period, women had higher success rates from 2015/16 to 2018/19, whereas men received larger amounts per award only in 2016/2017. When breaking down into GRF and ECS, women had a substantially higher success rate than men in the ECS (50.0\% vs. $29.2 \%$, respectively). For the GRF, women, and men had similar success rates (29.5\% vs. $29.3 \%)$.

Decomposition analysis. Using decomposition analysis, we examined the key components to account for the change in number of awards and the total amount of awards, namely: the number of eligible staff, the submission rate, the success rate, and the amount per award. More importantly, we took into account the gender effects to empirically address the four gender myths about research funding performance described earlier.

Changes in the number of awards. Table 2 presents the contribution of the various factors (\%) on the annual change of the number of awards between consecutive years over the academic years of our study period. For example, there was an increase of five awards between 2015/2016 and 2016/2017. These additional five awards can be attributed to improving the success rate of $137.2 \%$ ( $80.0 \%$ and $57.2 \%$ for men and women, respectively). However, the reduction in the submission rate for men and women contributed to a total decline $(-52.7 \%)$ on the number of awards $(-7.3 \%$ and $-45.4 \%$ for men and women, respectively).

From $2016 / 2017$ to $2017 / 2018$, while there was a decrease in the success rate (36.5-33.3\%), the negative effect was offset by an improvement of the submission rate (49.5-50.9\%). Men performed worse than women on the success rate, $29.0 \%$, and $39.1 \%$, respectively, on this occasion. Similarly, from $2018 / 2019$ to $2019 / 2020$, the reduction in success rate $(29.5-27.5 \%)$ was compensated by an increase in submission rate (59.2-65.1\%). The decomposition analysis suggested $-135.1 \%$ and $184.3 \%$, respectively, for the negative impact of the reduced success rate and the positive impact of improved submission rate.
For the latest round of annual change (from 2019/2020 to 2020/2021) with five more awards, the success rate was the most important factor (107.8\%). Although the submission rate reduction of men contributed to $-28.6 \%$ of the number of awards, the increase in success rate $(88.6 \%)$ for men was more than compensated for it, with a net contribution of $60 \%$ from men. The reduction in the number of eligible female applicants contributed to $-9.5 \%$ of the total effect. The contribution of the improvement of success and submission rate for women was $30.3 \%$ and $19.3 \%$, respectively, with a net contribution of $40 \%$ from women.

Changes in the amount of awards. The total funding received for men and women was HKD 36.7 million and HKD 34.4 million, respectively, and the average amount per award was HKD $612 \mathrm{~K}$ and HKD $662 \mathrm{~K}$, respectively (see Table 1). For the total amount of award, Table 3 suggests that the success rate, submission rate, and amount per award all contributed significantly to the increases in the total amount. For example, for from 2015/2016 to $2016 / 2017$, the success rate contributed to $291.7 \%$ (133.0\% and $158.7 \%$ for men and women) of the total increase of funding amount, whereas the reduction in the number of submissions contributed to $-138 \%(-12.1 \%$ and $-125.9 \%$ for men and women, respectively) of the total funding amount (i.e., reduction of HKD 1,233,500). Also, from 2019/2020 to 2020/2021, the increase of the total award amount by HKD 6,510,200 could be attributed to the success rate increase of men and women (HKD 2,678,800 [41.1\%] and HKD 704,300 [10.8\%], respectively). The submission rate increase of women further contributed to an increase of HKD 243,400 (3.7\%) but somewhat offset by the submission rate reduction of men $(-864,100[-13.3 \%])$. The reduction of the number of eligible female applicants contributed to HKD $-349,100(-5.4 \%)$ of the total funding amount. The success rate and the amount per award contributed to $52 \%$ and $49.7 \%$ for the increase in total funding amount. By contrast, the submission rate seems less important in determining the total funding amount (3.7\% only).

\section{Discussion}

Our study provides new empirical evidence for gender differences in research grants in social sciences is a leading university in Asia, namely, the University of Hong Kong (HKU). Women academics in social sciences there seem to do better in grant submission, success rate, and the average amount per award. When examining GRF and ECS separately, early-career academic women submitted more ECS proposals than men with a higher success rate, contributing to their receiving more research grants. These results go against the myth that hiring female academics would drag down research performance. Quite the opposite, we found that women performed as well, if not better, in securing research grants in social sciences. To improve gender parity, HKU recruited more talented women academics in social sciences in the last five years and also witnessed again in extramural competitive research funding.

Consistent with a prior UK study (Boyle et al., 2015), our findings indicated early-career women academics were more successful than their male counterparts. With increasing female representation in social sciences at HKU hiring in the past five years (from $20 \%$ to $40 \%$ ), the field has benefited from greater gender parity and, as a result, perhaps, awareness of conscious/ unconscious gender bias. Also, female social scientists have performed well as productive and visible scholars; their strong track records in research can enhance subsequent grant success. Third, via research and practices to highlight issues such as feminism, gender, sexuality, discrimination, and injustice, social scientists 


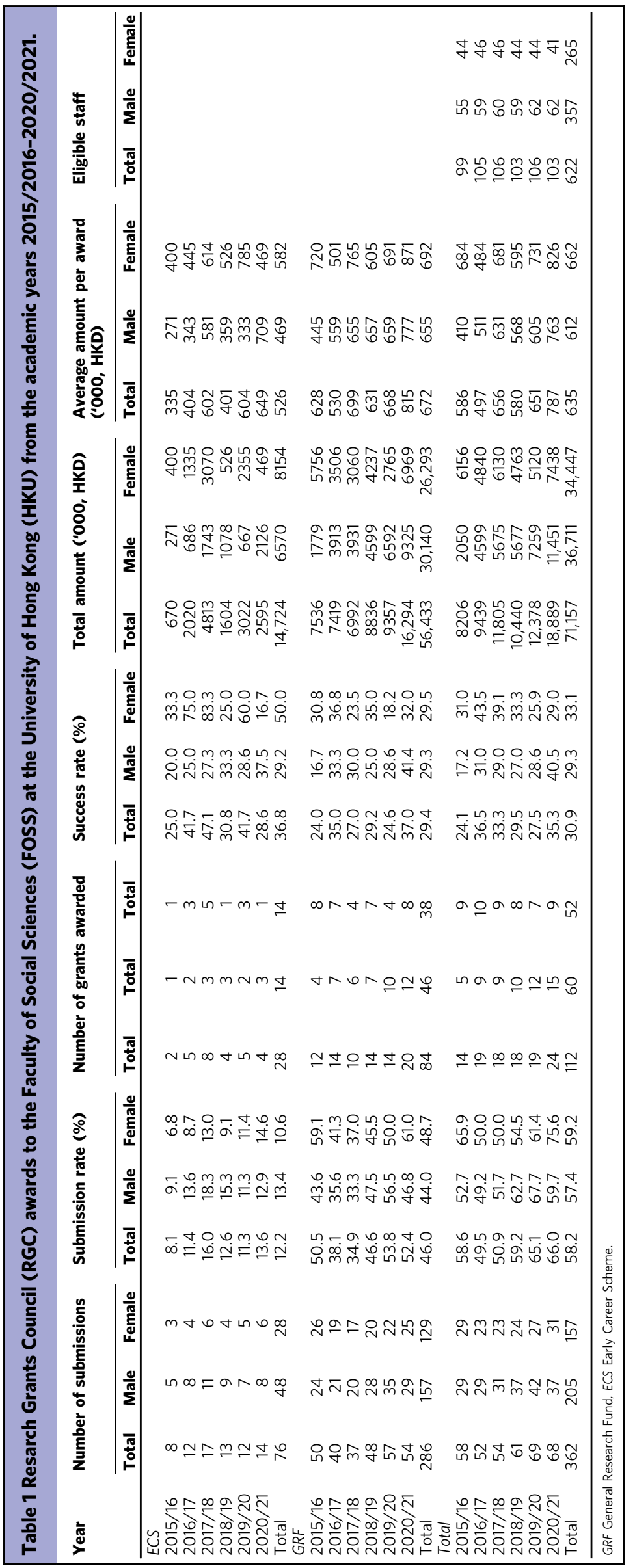




\begin{tabular}{|c|c|c|c|c|}
\hline Year & Success rate & Submission rate & Number of staff & Total \\
\hline \multicolumn{5}{|l|}{$15 / 16-16 / 17$} \\
\hline Male & 4.0 & -0.4 & 0.4 & 4.0 \\
\hline Male (\%) & 80.0 & -7.3 & 7.3 & 80.0 \\
\hline Female & 2.9 & -2.3 & 0.4 & 1.0 \\
\hline Female (\%) & 57.2 & -45.4 & 8.2 & 20.0 \\
\hline Total & 6.9 & -2.6 & 0.8 & 5.0 \\
\hline Total (\%) & 137.2 & -52.7 & 15.5 & 100.0 \\
\hline \multicolumn{5}{|l|}{$16 / 17-17 / 18$} \\
\hline Male & -0.6 & 0.5 & 0.2 & 0.0 \\
\hline Male (\%) & 62.1 & -46.8 & -15.3 & 0.0 \\
\hline Female & -1.0 & 0.0 & 0.0 & -1.0 \\
\hline Female (\%) & 100.0 & 0.0 & 0.0 & 100.0 \\
\hline Total & -1.6 & 0.5 & 0.2 & -1.0 \\
\hline \multirow{2}{*}{\multicolumn{5}{|c|}{$17 / 18-18 / 19$}} \\
\hline & & & & \\
\hline Male & -0.7 & 1.9 & -0.2 & 1.0 \\
\hline Male (\%) & NA & NA & NA & NA \\
\hline Female & -1.4 & 0.8 & -0.4 & -1.0 \\
\hline Female (\%) & NA & NA & NA & NA \\
\hline Total & -2.1 & 2.7 & -0.5 & 0.0 \\
\hline Total (\%) & NA & NA & NA & NA \\
\hline \multicolumn{5}{|l|}{$18 / 19-19 / 20$} \\
\hline Male & 0.6 & 0.8 & 0.5 & 2.0 \\
\hline Male (\%) & 64.9 & 84.3 & 50.8 & 200.0 \\
\hline Female & -2.0 & 1.0 & 0.0 & -1.0 \\
\hline Female (\%) & -200.0 & 100.0 & 0.0 & -100.0 \\
\hline Total & -1.4 & 1.8 & 0.5 & 1.0 \\
\hline Total (\%) & -135.1 & 184.3 & 50.8 & 100.0 \\
\hline \multicolumn{5}{|c|}{$19 / 20-20 / 21$} \\
\hline Male & 4.4 & -1.4 & 0.0 & 3.0 \\
\hline Male (\%) & 88.6 & -28.6 & 0.0 & 60.0 \\
\hline Female & 1.0 & 1.5 & -0.5 & 2.0 \\
\hline Female (\%) & 19.3 & 30.3 & -9.5 & 40.0 \\
\hline Total & 5.4 & 0.1 & -0.5 & 5.0 \\
\hline Total (\%) & 107.8 & 1.7 & -9.5 & 100.0 \\
\hline
\end{tabular}

are likely to disrupt traditional hierarchy (Mauthner and Edwards, 2010; Ho et al., 2018). Jointly, these factors may have counteracted a longstanding male-dominated culture in universities, funding organizations, and society at large (Munar, 2017), thereby promoting a more gender-equal evaluation of grant applications in social sciences. At HKU specifically, the HeforShe solidarity movement led by the former President and Vice-Chancellor Professor Peter Mathieson and the senior management team since 2015 has helped raise gender equity awareness and implemented gender-parity and family-friendly measures on campus and beyond (HKU, 2020b). Special professional development workshops on career development, as well as year-long mentoring programs, have also been offered to women academics (HKU, 2017) by the Office of one of the authors (Terry $\mathrm{Au}$ ) in her capacity as the Vice-President of Academic Staffing and Resources. Such initiatives may have helped empowered women academics to do well in research, including the increase in grant applications and successful awards.

Against the backdrop of universities in Asia and beyond, what we found in HKU can, in part, be explained by the international culture, recruitment policy, work practice, government policy, and family support in Hong Kong. Culturally speaking, Hong Kong has been known as a place where 'East meets West' (Schnurr and Mak, 2011; Aiston et al., 2020) due to its unique historical background. While preserving traditional Chinese values and practices in society, Hong Kong has evolved to become an international city with a diverse community. The identity, privileges, and power of women have changed amidst complex interactions of globalization, postcolonialism, and Chinese patriarchy (Lee, 2011). Hence, privileges of male dominance in the families and the work environments may have been less pronounced in Hong Kong than in other parts of Asia (Postiglione and Tang, 2008; Kang and Schnurr, 2010).

At $\mathrm{HKU}$, the recruitment of academic talents is open to the world without restriction in citizenship or nationality-and indeed with a preference for non-HKU graduates to reduce nepotism-and not biased by gender or any other demographics (HKU, 2020a). In fact, as reported in our study, new faculty appointments in social sciences in the past five years were made to more women than men, and most of them were not local candidates. Most early-career female assistant professors have a strong record of obtaining grants, especially those with overseas training and international collaborations. As a matter of fact, the male-to-female ratio of chair professors and endowed professors in FOSS from 2015 to 2020 is 9:11.

Institutional support and female-friendly workplaces have been found to significantly increase the success rates of grant applications among female academics (Teodorescu, 2000; Jung, 2012). At $\mathrm{HKU}$, the institution provides research support for early career academics without any gender consideration. There has also been advocacy and engagement of gender equity around the campus (e.g., the HeForShe Initiative), with a recent President \& ViceChancellor being a strong advocate (HKU, 2017, 2020b). The HeForShe Movement has raised awareness of gender equality in the participatory institutions, including HKU (UN Women, 2016). In addition, HKU's Equal Opportunity Unit set up a Working Group on Race, Gender Identity, Sexual Orientation, and Family Status in 2014 to examine HKU's equality policies. Since 2016, the Vice-President of Academic Staffing and Resources has led efforts to enhance gender equity, women's access to leadership opportunities, and family-friendly policies in HKU. The Equal Opportunity Unit assists in creating and safeguarding an inclusive environment on campus.

At the government policy level in Hong Kong, the Labor Department in 2020 has successfully spearheaded an extension of maternity leave from 10 weeks to 14 weeks with $80 \%$ of wage coverage. Notably, in such salary coverage at HKU is $100 \%$ during the 14 weeks of maternity leave. There are also accompanied family-friendly measures to offer other support (e.g., teaching reduction for the birth of a child or adoption of a young child; additional leave days for taking care of family members with medical needs). These policies further reduced the burden of raising young children and caring for elderly parents among women academics-in line with the government urging employers to adopt family-friendly measures (Siu et al., 2006).

The common practice of employing live-in foreign domestic helpers in Hong Kong means that women academics (and professionals in general) have considerable help for house chores and childcare. This societal culture has rendered family responsibilities less gendered on the division of household labor between women professionals and their partners/spouses. Indeed, contrary to the findings in the West (Watson and Hjorth, 2015; McAllister et al., 2016), Aiston (2014) found that motherhood did not have a negative impact on woman academics' research productivity in Hong Kong, as measured by the number of books and journal articles published. Together, these factors have yielded a more gender-equitable culture at HKU and in Hong Kong. They may also have contributed our findings that the success of grant applications seemed to depend significantly on applicants' time and efforts, regardless of gender-in line with previous studies (Teodorescu, 2000; Jung, 2012).

Our results suggest promising next steps for universities, research institutes, funding agencies, and the society at large to narrow the gender gap across disciplines. Within departments, faculties, and universities, although female Principal Investigators 
Table 3 Decomposition analysis for changes in the amount of awards ('000, HKD).

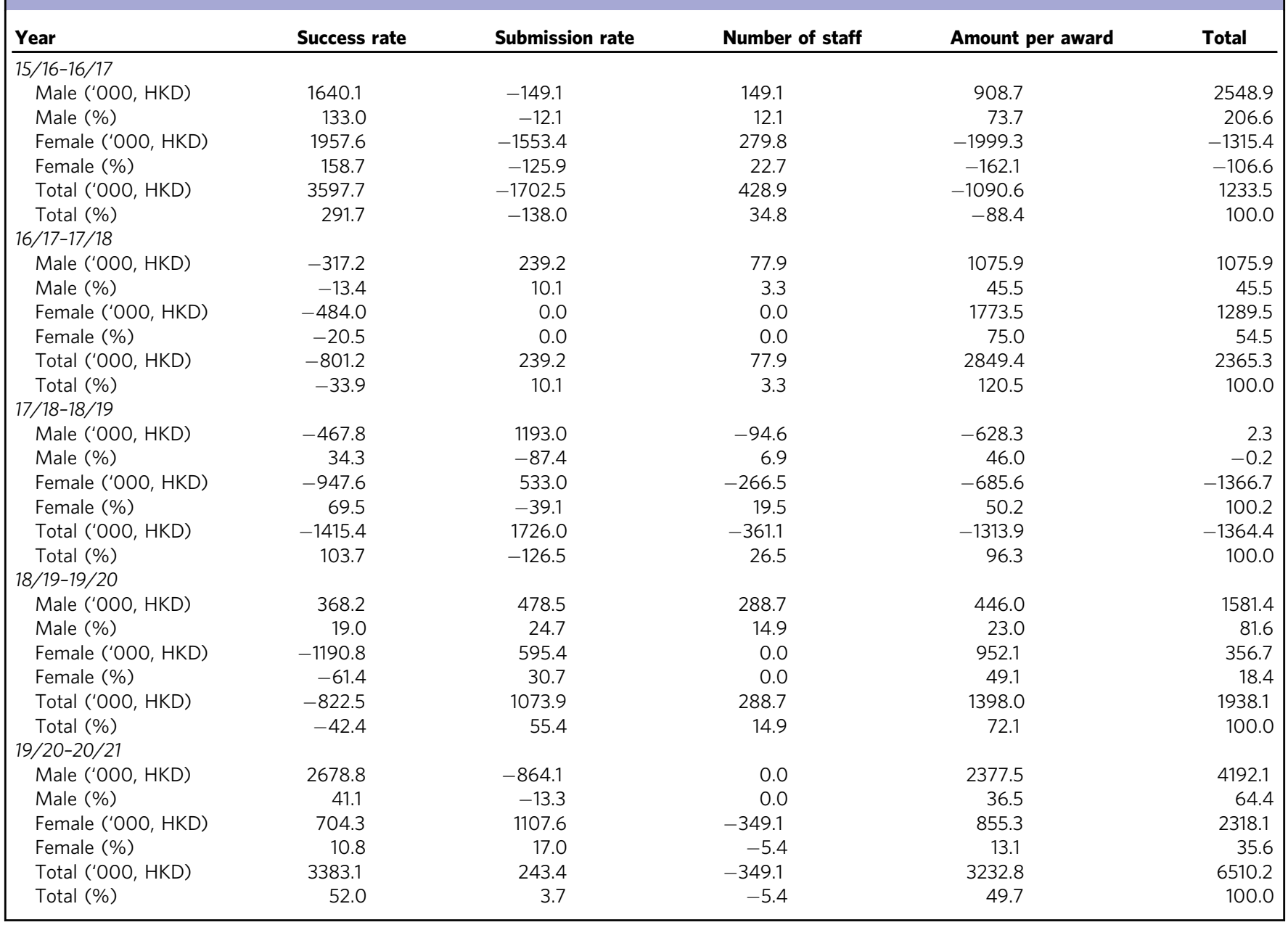

(PIs) were shown to perform better than male PIs in early career, proactive strategies should be promoted to plug the holes in the 'leaky pipeline' (Ma et al., 2018; Gewin, 2019; Grogan, 2019; Weigel et al., 2020). For example, continuous support for female academics through mentorship programs and early career development may reduce productivity disparities and encourage their continuous grant seeking in the mid-career and seniorcareer stages (Mejia, 2010; Holliday et al., 2014). Bold restructuring of leadership positions and opportunities for advanced career development, including offering more flexible tenure and promotion pathways for women (Mejia, 2010; Zakaib, 2011), or extending the age criteria for women to apply for senior scientific career awards (Ma et al., 2018) have been suggested to retain female researchers beyond their early stage of the academic career. Universities should also consider involving male staffs in the promotion of gender equity, such as providing gender capacity-development training to increase awareness, identify challenges, and find solutions to empower female colleagues in workplaces. For example, the Women in Science at Columbia supports, advances, and reaches out to women in STEM at Columbia University by organizing symposiums and workshops of gender bias and peer-support (Women in Science at Columbia, 2020). At HKU, a year-long mentoring and career coaching program has been offered to 10 female associate professors each year-each nominated by their Deans since 2017 (http://vpasr. hku.hk/hku-10-mentorship-program.html). Continuous efforts to create integrated support for working women are needed, including more informed decision-making tools for family and career, more family-friendly meeting times and child care support, allowing part-time working plan, remote working, and paid parental leave for both fathers and mothers (Mejia, 2010; Zakaib, 2011; Boyle et al., 2015; Vassie et al., 2020).

For funding agencies, strategies to shape the representativeness of women in research funders, universities, departments, and other committees responsible for public spending can be impactful. For example, the Athena SWAN initiative requires HEIs to obtain an Athena SWAN silver awards as a pre-requisite for certain large-scale funding from the National Institute for Health Research in the UK (Advance HE, 2019; Equality Challenge Unit, 2019b). The initiative was found to encourage gender equity and to be associated with increased rates of female leaders in managerial and professoriate positions (Ovseiko et al., 2016; Xiao et al., 2020). In China, recent studies found raising the maximum age for applying for the Young Scientist Fund by the National Natural Science Foundation of China (NSFC) has increased the representation of female applicants from $37 \%$ to $48 \%$ since 2011 , and female awardees also increased from $33 \%$ to 43\% (Ma et al., 2018).

Both universities and funding agencies would do well to implement routine data collection and publication related to the staff demographics, funding applications, success rates, award sizes by gender and disciplines. Such transparent evidence would not only help prospective applicants to assess the institutional culture but also facilitate policy design targeting specific disciplines and sectors. Upon funding awarded, celebrating women's achievement publicly and across platforms can enhance the 
recognition and visibility of excellent female researchers (Boyle et al., 2015).

Lastly, social campaigns, such as the Time to Change (TTC) program launched in 2009 in the UK, have been found to reduce stigma, discriminatory behaviors while improving public attitudes toward people with mental illness (Henderson and Thornicroft, 2009; Xiao et al., 2020). Hence, gender-equity national and regional campaigns could also bring together funding agencies, a consortium of prominent universities, and societies to develop coordinated approaches to reducing gender inequalities across social sciences and STEM disciplines in science.

\section{Strengths and limitations}

This study has three major strengths. First, we used decomposition analysis to identify the relative effects of academic staff demographics, submission rates, and success rates for overall changes in research grant funding. Second, we examined ECS and GRF together and separately, which revealed gender differences for early-career academics favoring women (i.e., ECS). Third, our data span successive annual changes in research funding from $2015 / 2016$ to $2020 / 2021$ were awarded by a major funding agency (RGC of Hong Kong) for a major research-oriented university. Therefore, our study makes an important contribution to understanding female academics' position and status regarding grant success, going beyond the Western context to identify commonality and differences.

We are mindful of the following limitations of this study. First, we did not collect data on or control for age, domain or research, and specific academic positions (e.g., Assistant Professor, Associate Professor, Professors), which can affect gender bias in grant funding (Witteman et al., 2019a). Second, we focused on one institution, not all the UGC-funded universities in Hong Kong. There might be heterogeneity across universities in terms of research grant funding. Third, this study contributes to the literature about the gender (dis)parity of research grant success in social sciences. It should be noticed that the sub-fields and research domains in social sciences could be more diverse than the disciplines included here. Lastly, we did not examine research-support activities or other initiatives within the University that may affect extramural research funding results.

\section{Conclusion}

The empirical results revealed that women made a solid contribution to compete successfully for grants in social sciences. The performance of the newly recruited early-career woman colleagues is very promising. For the number of awards, it is important to improve the submission rate, since the success rate did not seem to be negatively affected (or diluted) by a higher submission rate. Importantly, more successful awards can build grant-writing capacity not only for the successful applicants but also via experience sharing for their colleagues. Raising the submission rate (by applying more frequently and mobilizing and supporting more colleagues to apply) and success rate simultaneously attests to this. For award amounts, all three factors-submission rate, success rate, and individual grant amounts-are significant in determining the total amount of awards received by the institution. It is pleasing to see no evidence of gender bias against women in social science regarding grant fundings success in Hong Kong, and this can and should happen in other places.

\section{Data availability}

The datasets generated during and/or analyzed during the current study are not publicly available due to data privacy issue from the faculty as it concern the individual performance. They are available from the corresponding author on reasonable request.
Received: 22 July 2020; Accepted: 3 November 2020;

Published online: 09 December 2020

\section{References}

Advance HE (2019) Athena SWAN Charter. https://www.ecu.ac.uk/equalitycharters/athena-swan/

Aiston SJ (2014) Leading the academy or being led? Hong Kong women academics. High Educ Res Dev 33(1):59-72. https://doi.org/10.1080/07294360.2013.864618

Aiston SJ, Fo CK, Law WW (2020) Interrogating strategies and policies to advance women in academic leadership: the case of Hong Kong. J High Educ Policy Manag 42(3):347-364. https://doi.org/10.1080/1360080x.2020.1753393

Aiston SJ, Jung J (2015) Women academics and research productivity: an international comparison. Gend Educ 27(3):205-220. https://doi.org/10.1080/ 09540253.2015.1024617

Bautista-Puig N, Garcia-Zorita C, Mauleon E (2019) European Research Council: excellence and leadership over time from a gender perspective. Res Eval 28 (4):370-382. https://doi.org/10.1093/reseval/rvz023

Bedi G, Van Dam NT, Munafo M (2012) Gender inequality in awarded research grants. Lancet 380(9840):474

Bornmann L, Mutz R, Daniel H-D (2007) Gender differences in grant peer review: a meta-analysis. J Inf 1(3):226-238

Boyle PJ, Smith LK, Cooper NJ, Williams KS, O'Connor H (2015) Gender balance: women are funded more fairly in social science. Nature 525(7568):181-183

Burns KE, Straus SE, Liu K, Rizvi L, Guyatt G (2019) Gender differences in grant and personnel award funding rates at the Canadian Institutes of Health Research based on research content area: a retrospective analysis. PLoS Med 16(10):e1002935

Chang Q, Yip PS, Chen YY (2019) Gender inequality and suicide gender ratios in the world. J Affect Disord 243:297-304

DeAro J, Bird S, Mitchell Ryan S (2019) NSF ADVANCE and gender equity: past, present and future of systemic institutional transformation strategies. Equal Divers Incl 38(2):131-139. https://doi.org/10.1108/EDI-09-2017-0188

Ding WW, Murray F, Stuart TE (2006) Gender differences in patenting in the academic life sciences. Science 313(5787):665-667. https://doi.org/10.1126/ science. 1124832

Duke University $(2020,2018)$ Our faculty. https://trinity.duke.edu/faculty

Edmunds LD, Ovseiko PV, Shepperd S, Greenhalgh T, Frith P, Roberts NW, Buchan AM (2016) Why do women choose or reject careers in academic medicine? A narrative review of empirical evidence. Lancet 388 (10062):2948-2958. https://doi.org/10.1016/S0140-6736(15)01091-0

Equality Challenge Unit (2019a) About advance HE's Athena SWAN charter. https://www.ecu.ac.uk/equality-charters/athena-swan/about-athena-swan/

Equality Challenge Unit (2019b) Athena SWAN resources. https://www.ecu.ac.uk/ equality-charters/athena-swan/athena-swan-resources/

Finkel A (2013) Gender equality in Australian academies. Nature 498 (7453):171-171

Forscher PS, Cox WTL, Brauer M, Devine PG (2019) Little race or gender bias in an experiment of initial review of NIH R01 grant proposals. Nat Hum Behav 3(3):257-264. https://doi.org/10.1038/s41562-018-0517-y

Gewin V (2019) Plugging the leaky pipeline for UK female chemists. Nature 565 (7737):389-390

Ghiasi G, Lariviere V, Sugimoto CR (2015) On the compliance of women engineers with a gendered scientific system. PLoS ONE 10(12). https://doi.org/10.1371/ journal.pone.0145931

Ginther DK, Kahn S, Schaffer WT (2016) Gender, race/ethnicity, and National Institutes of Health R01 research awards: is there evidence of a double bind for women of color? Acad Med 91(8):1098

Grogan KE (2019) How the entire scientific community can confront gender bias in the workplace. Nat Ecol Evol 3(1):3-6. https://doi.org/10.1038/s41559-018-0747-4

Hechtman LA, Moore NP, Schulkey CE, Miklos AC, Calcagno AM, Aragon R, Greenberg JH (2018) NIH funding longevity by gender. Proc Natl Acad Sci USA 115(31):7943-7948

Henderson C, Thornicroft G (2009) Stigma and discrimination in mental illness: time to change. Lancet 373(9679):1928-1930

HKU (2017) Gender on the table. https://www4.hku.hk/pubunit/Bulletin/ 2017_Mar_Vol.18_No.2/cover_story/pagel.html

HKU (2020a) Career opportunities. https://jobs.hku.hk/en/listing/

HKU (2020b) HeForShe at HKU. https://www.hku.hk/about/policies_reports/ HeForSheatHKU.html

Ho PSY, Jackson S, Cao S, Kwok C (2018) Sex with Chinese characteristics: sexuality research in/on 21st-century China. J Sex Res 55(4-5):486-521

Holliday EB, Jagsi R, Wilson LD, Choi M, Thomas CR, Fuller CD (2014) Gender differences in publication productivity, academic position, career duration, and funding among U.S. academic radiation oncology faculty. Acad Med 89 (5):767-773. https://doi.org/10.1097/acm.0000000000000229 
Holmes MA, O'connell S, Frey C, Ongley L (2008) Gender imbalance in US geoscience academia. Nat Geosci 1(2):79-82

Hosseinpoor AR, Williams JS, Jann B, Kowal P, Officer A, Posarac A, Chatterji S (2012) Social determinants of sex differences in disability among older adults: a multi-country decomposition analysis using the World Health Survey. Int J Equity Health 11(1):1-8

Jung J (2012) Faculty research productivity in Hong Kong across academic discipline. High Educ Stud 2(4). https://doi.org/10.5539/hes.v2n4p1

Kaatz A, Lee Y-G, Potvien A, Magua W, Filut A, Bhattacharya A, Carnes M (2016) Analysis of National Institutes of Health R01 application critiques, impact, and criteria scores: does the sex of the principal investigator make a difference? Acad Med 91(8):1080-1088

Kang MA, Schnurr S (2010) From high society to workplace reality: an analysis of gendered discourses in media and workplaces in Hong Kong. In: Holmes J, Marra M (Eds.) Femininity, feminism and gendered discourse: a selected and edited collection of papers from the fifth International Language and Gender Association Conference (IGALA5). Cambridge Scholars Publishing, Cambridge, pp. 171-190

Kwok CL, Lee CK, Lo WT, Yip PS (2017) The contribution of ageing to hospitalisation days in Hong Kong: a decomposition analysis. Int J Health Policy Manag 6(3):155

Larivière V, Ni C, Gingras Y, Cronin B, Sugimoto CR (2013) Bibliometrics: global gender disparities in science. Nat News 504(7479):211

Latimer J, Cerise S, Ovseiko PV, Rathborne JM, Billiards SS, El-Adhami W (2019) Australia's strategy to achieve gender equality in STEM. Lancet 393 (10171):524-526. https://doi.org/10.1016/s0140-6736(18)32109-3

Lee EW-Y (2011) Gender and change in Hong Kong: globalization, postcolonialism, and Chinese patriarchy. UBC Press

Lerback J, Hanson B (2017) Journals invite too few women to referee. Nature 541 (7638):455-457

Luke C (2000) One step up, two down: Women in higher education management in Southeast Asia. In: Malcolm T (ed) Academic work and life: what it is to be an academic, and how this is changing, vol. 1. Emerald Group Publishing Limited, pp. 285-305

Ma Y, Zhao YD, Gong X, Sun L, Zheng YH (2018) Close the gender gap in Chinese science. Nature 557(7703):25-27

Madden D (2010) Gender differences in mental well-being: a decomposition analysis. Soc Indic Res 99(1):101-114

Marsh HW, Jayasinghe UW, Bond NW (2011) Gender differences in peer reviews of grant applications: a substantive-methodological synergy in support of the null hypothesis model. J Inf 5(1):167-180

Mauthner NS, Edwards R (2010) Feminist research management in higher education in Britain: possibilities and practices. Gend Work Organ 17 (5):481-502. https://doi.org/10.1111/j.1468-0432.2010.00522.x

McAllister D, Juillerat J, Hunter J (2016) What stops women getting more grants? Nature 529(7587):466-466. https://doi.org/10.1038/529466d

Mejia R (2010) Gender stop-gaps. Nature 465(7299):832-833. https://doi.org/ 10.1038/nj7299-832a

Moss-Racusin CA, Dovidio JF, Brescoll VL, Graham MJ, Handelsman J (2012) Science faculty's subtle gender biases favor male students. Proc Natl Acad Sci USA 109(41):16474-16479. https://doi.org/10.1073/pnas.1211286109

Munar AM (2017) To be a feminist in (tourism) academia. Anatolia-Int J Tour Hosp Res 28(4):514-529. https://doi.org/10.1080/13032917.2017.1370777

National Research Council (2010) Gender differences at critical transitions in the careers of science, engineering, and mathematics faculty. National Academies Press

National Science Foundation (2001) ADVANCE increasing the participation and advancement of women in academic science and engineering careers. National Science Foundation, Arlington

Nielsen MW, Bloch CW, Schiebinger L (2018) Making gender diversity work for scientific discovery and innovation. Nat Hum Behav 2(10):726-734

Ovseiko PV, Chapple A, Edmunds LD, Ziebland S (2017) Advancing gender equality through the Athena SWAN Charter for Women in Science: an exploratory study of women's and men's perceptions. Health Res Policy Syst 15(1). https://doi.org/10.1186/s12961-017-0177-9

Ovseiko PV, Greenhalgh T, Adam P, Grant J, Hinrichs-Krapels S, Graham KE, Al, Olaqi NM (2016) A global call for action to include gender in research impact assessment. Health Res Policy Syst 14(1):50

Pohlhaus JR, Jiang H, Wagner RM, Schaffer WT, Pinn VW (2011) Sex differences in application, success, and funding rates for NIH extramural programs. Acad Med 86(6):759-767. https://doi.org/10.1097/ACM.0b013e31821836ff

Postiglione GA, Tang HHH (2008) A preliminary review of the Hong Kong CAP data. Paper presented at the changing academic profession in international comparative and quantitative perspectives.

Quacquarelli Symonds (2020) QS Ranking: The University of Hong Kong. https:// www.topuniversities.com/universities/university-hong-kong/undergrad

Ruan, N (2020) Accumulating academic freedom for intellectual leadership: women professors' experiences in Hong Kong. Educ Philos Theory 1-11. https://doi.org/10.1080/00131857.2020.1773797
Schmidt EK, Ovseiko PV, Henderson LR, Kiparoglou V (2020) Understanding the Athena SWAN award scheme for gender equality as a complex social intervention in a complex system: analysis of Silver award action plans in a comparative European perspective. Health Res Policy Syst 18(1):19. https:// doi.org/10.1186/s12961-020-0527-x

Schnurr S, Mak B (2011) Leadership in Hong Kong. Is gender really not an issue Gend Lang 5(2):343-371. https://doi.org/10.1558/genl.v5i2.337

Sheltzer JM (2018) Gender disparities among independent fellows in biomedical research. Nat Biotechnol 36(10):1018-1021

Shen H (2013) Mind the gender gap. Nature 495(7439):22

Siu O-l, Chow SL, Phillips DR, Lin L (2006) An exploratory study of resilience among Hong Kong employees: Ways to happiness. In Ng Y-K, Ho LS (eds.), Happiness and public policy: Theory, case studies, and implications (pp. 209-220). Palgrave Macmillan, New York

Symonds MRE, Gemmell NJ, Braisher TL, Gorringe KL, Elgar MA (2006) Gender differences in publication output: towards an unbiased metric of research performance. PLoS ONE 1(2). https://doi.org/10.1371/journal.pone.0000127

Tang HHH (2018) Women and intellectual leadership in East Asia's academic professions: a review of the literature. In: Inclusive leadership in higher education: international perspectives and approaches. Rouledge, pp. 29-45.

Tang HHH (2019) World-class universities and female leadership in the academic profession: case studies of East Asian higher education. In Neubauer DE, Kaur S (eds.). Palgrave Macmillan, Cham. https://doi.org/10.1007/978-3-030-02795-7_4

Teodorescu D (2000) Correlates of faculty publication productivity: a crossnational analysis. Higher Educ 39(2):201-222

Times Higher Education (2020) Times Higher Education World University Rankings 2020. https://www.timeshighereducation.com/world-universityrankings/university-hong-kong

UN Women (2016) HeForShe Impact $10 \times 10 \times 10$ University Parity Report. https://www.heforshe.org/sites/default/files/2018-11/HeForShe\%20University \%20Parity\%20Report\%202016.pdf

University Grants Committee (2020a) Early career application. https://www.ugc. edu.hk/eng/rgc/funding_opport/early_career/application.html

University Grants Committee (2020b) Funding results. University Grants Committee

University Grants Committee (2020c) General Research Fund. https://www.ugc. edu.hk/eng/rgc/funding_opport/general_research_fund.html

University Grants Committee. (2020d) What can I apply for? https://www.ugc.edu. hk/eng/rgc/funding_opport/apply.html

van den Besselaar P, Leydesdorff L (2009) Past performance, peer review and project selection: a case study in the social and behavioral sciences. Res Eval 18(4):273-288. https://doi.org/10.3152/095820209x475360

Vassie C, Smith S, Leedham-Green K (2020) Factors impacting on retention, success and equitable participation in clinical academic careers: a scoping review and meta-thematic synthesis. BMJ Open 10(3). https://doi.org/ 10.1136/bmjopen-2019-033480

Watson D, Hjorth J (2015) Women's grants lost in inequality ocean. Nature 519 (7542):158-158. https://doi.org/10.1038/519158d

Weigel KS, Kubik-Huch RA, Gebhard C (2020) Women in radiology: why is the pipeline still leaking and how can we plug it? Acta Radiol 61(6):743-748. https://doi.org/10.1177/0284185119881723

West JD, Jacquet J, King MM, Correll SJ, Bergstrom CT (2013) The role of gender in scholarly authorship. PLoS ONE 8(7):e66212. https://doi.org/10.1371/ journal.pone. 0066212

Witteman HO, Hendricks M, Straus S, Tannenbaum C (2019a) Are gender gaps due to evaluations of the applicant or the science? A natural experiment at a National Funding Agency. Lancet 393(10171):531-540

Witteman HO, Hendricks M, Straus S, Tannenbaum C (2019b) Gender bias in CIHR Foundation grant awarding. Lancet 394(10214):E41-E42

Women in Science at Columbia (2020) Women in Science at Columbia. https:// womeninscienceatcolumbia.org/

Xiao Y, Pinkney E, Au TKF, Yip PSF (2020) Athena SWAN and gender diversity: a UK-based retrospective cohort study. BMJ Open 10(2):e032915. https://doi. org/10.1136/bmjopen-2019-032915

Yip PS, Wong JH, Li BY, Zhang Y, Kwok CL, Chen MN (2017) Assessing the impact of population dynamics on poverty measures: a decomposition analysis. Soc Indic Res 134(2):531-545

Zakaib GD (2011) Science gender gap probed. Nature 470(7333):153-153

Zhang FQ, Yan EJ, Niu X, Zhu YJ (2018) Joint modeling of the association between NIH funding and its three primary outcomes: patents, publications, and citation impact. Scientometrics 117(1):591-602. https://doi.org/10.1007/ s11192-018-2846-z

\section{Acknowledgements}

The authors are grateful to the support of Prof. Will Hayward (the Dean) and Ms. Cheuk Wing of the Faculty of Social Sciences and Ms. Agnes Ip of the Registry at the University of Hong Kong to facilitate the study, and we thank the two reviewers and Associate Editor for helpful feedback. The research was supported by the Karen Ho Eugene Chuang Endowed Professorship of Diversity and Equity. 


\section{Competing interests}

The authors declare no competing interests.

\section{Additional information}

Supplementary information is available for this paper at https://doi.org/10.1057/s41599020-00656-y.

Correspondence and requests for materials should be addressed to P.S.F.Y.

Reprints and permission information is available at http://www.nature.com/reprints

Publisher's note Springer Nature remains neutral with regard to jurisdictional claims in published maps and institutional affiliations. (c) (i) Open Access This article is licensed under a Creative Commons Attribution 4.0 International License, which permits use, sharing, adaptation, distribution and reproduction in any medium or format, as long as you give appropriate credit to the original author(s) and the source, provide a link to the Creative Commons license, and indicate if changes were made. The images or other third party material in this article are included in the article's Creative Commons license, unless indicated otherwise in a credit line to the material. If material is not included in the article's Creative Commons license and your intended use is not permitted by statutory regulation or exceeds the permitted use, you will need to obtain permission directly from the copyright holder. To view a copy of this license, visit http://creativecommons.org/ licenses/by/4.0/

(C) The Author(s) 2020 